\title{
Strategic approach of an urban 900-bed academic medical center to combat Clostridium difficile infection transmission using staff engagement
}

Courtney Mitchell, MPH; Kelly Zabriskie, CIC

Thomas Jefferson University Hospital

\section{Background}

- Clostridium difficile infection (CDI) caused nearly 500,000 illnesses with 29,000 deaths in the United States

- Preventing hospital-associated Clostridium difficile infection (HA-CDI) is crucial to modern healthcare systems for reducing mortality, healthcare costs and length of stay

- There are multiple risk factors for CDI transmission in healthcare settings:

- Failure to comply with hand hygiene

- Ineffective equipment and surface cleaning

- Diagnosis delays

\section{Objective}

- Promptly engage hospital staff in discussion after HA-CDI to identify gaps and reduce infection rates in our facility.

Methods

- After identifying a HA-CDI, infection control and the unit's clinical nurse specialist coordinated an interdisciplinary huddle

- Nursing, environmental services, physicians, pharmacy and ancillary staff were invited to attend the huddle

- A CDI huddle guide (Figure 1.) was utilized to prompt conversation around the case and collect data about the patient: including risk factors such as advanced age, antibiotics usage and previous admission from an outside facility

- Other variables including environmental factors, hand hygiene, and any missed opportunities or barriers to diagnosis were identified

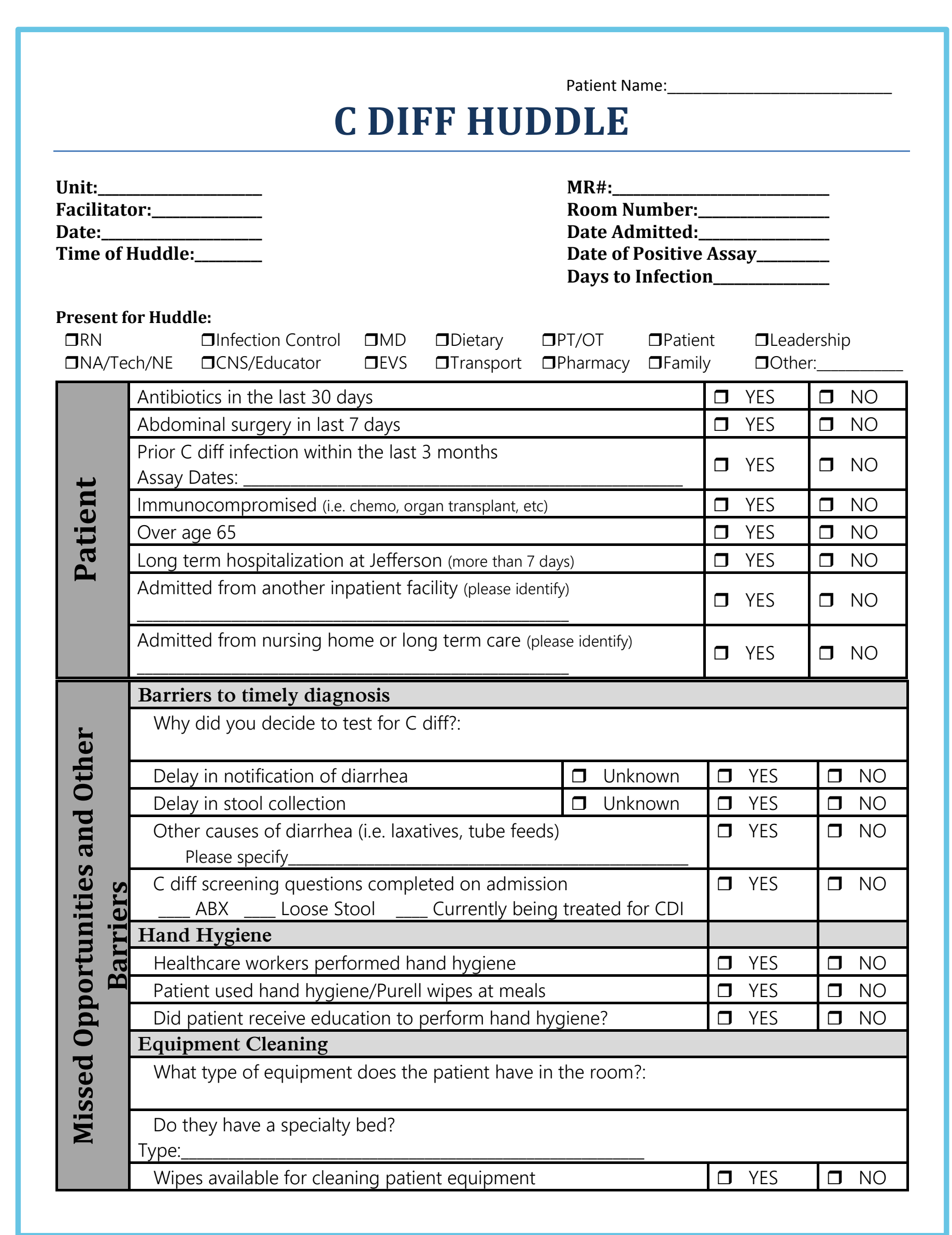

Figure 1. Page one of the huddle guide used to collect information and guide discussion.

\section{Results}

- Completed 48 CDI huddles over the course of 14 weeks

- $40 \%$ of cases experienced a delay in diagnosis

- $63 \%$ of patients with HA-CDI had two or more risk factors (i.e. antibiotics use, $\geq 65$ years of age, admitted from an outside facility etc.)

- Clinical team member present for $52 \%$ of huddles $(n=25)$

- $85 \%$ of patients received verbal screening questions during the nursing admission history $(n=41)$

\begin{tabular}{|l|l|}
\multicolumn{1}{|c|}{ Findings } & \multicolumn{1}{c|}{ Actions } \\
\hline $\begin{array}{l}\text { Verbalized perceived workflow } \\
\text { barriers affecting transmission } \\
\text { or diagnosis }\end{array}$ & $\begin{array}{l}\text { Unit specific interventions and } \\
\text { use of CDI prevention tools and } \\
\text { resources (i.e. Enteric Bundle } \\
\text { and Diarrhea Decision tree) }\end{array}$ \\
\hline Unclear lab testing guidelines & $\begin{array}{l}\text { Educate staff on appropriate } \\
\text { stool sample submission to lab }\end{array}$ \\
\hline $\begin{array}{l}\text { Gaps in communication } \\
\text { between clinical staff and } \\
\text { nursing }\end{array}$ & $\begin{array}{l}\text { Encourage nursing to report } \\
\text { new onset diarrhea promptly } \\
\text { to clinical team }\end{array}$ \\
\hline $\begin{array}{l}\text { Incomplete documentation } \\
\text { of stool }\end{array}$ & $\begin{array}{l}\text { Highlight education for } \\
\text { accurate and descriptive stool } \\
\text { documentation }\end{array}$ \\
\hline Patient hand hygiene & $\begin{array}{l}\text { Multidisciplinary effort with } \\
\text { dietary and nursing to } \\
\text { encourage patient hand } \\
\text { hygiene opportunities }\end{array}$ \\
\hline
\end{tabular}

Conclusions

- Engaging staff in CDI huddles revealed delays in testing and gaps in education, prompting implementation of a nursing driven diarrhea decision tree

- The huddles increase awareness around CDI transmission, further education to clinical and support staff, and empower unit staff to be prevention champions

Disclosures

Nothing to disclose 